\title{
COUPLED SYSTEMS OF FRACTIONAL $\nabla$-DIFFERENCE BOUNDARY VALUE PROBLEMS
}

\section{YousEF GHOLAMI AND KAZEM GHANBARI}

Abstract. In this paper, we study the existence of solutions for a coupled system of two-point fractional $\nabla$-difference boundary value problems of the form

$$
\begin{aligned}
& \left(\begin{array}{l}
\nabla_{a^{+}}^{\alpha} u(t) \\
\nabla_{a^{+}}^{\beta} v(t)
\end{array}\right)+\left(\begin{array}{l}
f(t, v(t) \\
g(t, u(t))
\end{array}\right)=0, \\
& \left(\begin{array}{c}
u(a+1) \\
u(b+1)
\end{array}\right)=\left(\begin{array}{l}
0 \\
0
\end{array}\right)=\left(\begin{array}{l}
v(a+1) \\
v(b+1)
\end{array}\right),
\end{aligned}
$$

where $1<\alpha, \beta \leqslant 2, t \in[a+2, b+1]_{\mathbb{N}}=\{a+2, a+3, \ldots, b, b+1\}, a, b \in \mathbb{Z}$ such that $a \geqslant$ $0, b \geqslant 3$ and the functions $f, g:[a+2, b+1]_{\mathbb{N}} \times \mathbb{R} \rightarrow \mathbb{R}$ are continuous. Our analysis relies on the Green functions and the nonlinear alternative of Leray-Schauder and Krasnoselśkii-Zabreiko fixed point theorems. At the end we give some numerical examples to illustrate the main results.

Mathematics subject classification (2010): 34A08, 39A12, 34A12, 34B15, 39A10.

Keywords and phrases: discrete fractional calculus, boundary value problems, fixed point theorem, existence of solutions.

\section{REFERENCES}

[1] T. Abdeljawad, Dual identities in fractional difference calculus within Riemann, arXiv:1112$5795 v 2,(2013)$.

[2] F.M. Aтіci, P.W. Eloe, A Transform Method in Discrete Fractional Calculus, Int. J. Difference Equ. Vol. 2, No. 2, (2007), 165-176.

[3] F.M. Atici, P.W. Eloe, Two-point boundary value problems for finite fractional difference equations, J. Difference Equ. Appl. Vol. 17, No. 4, (2011), 445-456.

[4] F.M. Atici, P.W. Eloe, Initial value problems in discrete fractional calculus, Proc. Amer. Math. Soc. Vol. 137, No. 3, (2009), 981-989.

[5] F.M. Atici, P.W. Eloe, Discrete fractional calculus with the nabla operator, Electron. J. Qual. Theory Differ. Equ., Spec. Ed. I, No. 3, (2009), 1-12.

[6] R.A.C. Ferreira, Some discrete fractional Lyapunov-type inequalities, Fractional. Differ. Calc, Vol. 5, No.1, (2015), 87-92.

[7] C.S. GOODRICH, Existence and uniqueness of solutions to a fractional difference equation with nonlocal conditions, Comput. Math. Appl., 61, (2011), 191-202.

[8] C. Goodrich, A.C. Peterson, Discrete fractional calculus, Springer, (2015).

[9] Y. Gholami, K. Ghanbari, New classes of Lyapunov type inequalities of fractional $\Delta$-difference Sturm-Liouville problems with applications, Bull. Iranian Math. Soc. In press.

[10] N. Kosmatov, Solutions to a class of nonlinear differential equations of fractional order, Electron. $J$. Qual. Theory Differ. Equ., (2009), No. 20, 1-10.

[11] A.A. Kilbas, H.M. Srivastava, J.J. Trujillo, Theory and Applications of Fractional Differential Equations, North-Holland mathematics studies, Elsevier science, 204, (2006).

[12] I. Podlubny, Fractional Differential Equations, Mathematics in Science and Applications, Academic Press, New York, 19, (1999). 
[13] X. ZHAO, W. GE, Unbounded solutions for a fractional boundary value problem on the infinite interval, Acta. Appl. Math, 109, (2010), 495-505. 